\title{
Acoustic events on a small seismological network - shock waves from thunder and fireballs
}

\author{
Peter H. Voss, Trine Dahl-Jensen and Tine B. Larsen
}

The Geological Survey of Denmark and Greenland (GEUS) operates a network of seismic stations in Denmark primarily to detect earthquakes. But from time to time other sources than earthquakes generate seismic signals that are detected at the stations. Here we show that both meteoroids and thunder have generated seismic signals with high signal-to-noise ratios at some of GEUS' seismic stations (Fig. 1). The purpose of the seismic stations is to provide data for the earthquake database of the Kingdom of Denmark, hosted and maintained by GEUS. In order to avoid that the earthquake database is contaminated by other events not related to tectonism, these events are given special markers when possible.

\section{Meteoroids}

In their fall through the atmosphere two meteoroids generated sonic signals close to Danish seismic stations with sufficient energy to cause seismic signals (Fig. 2). Fireballs of the meteoroids were observed. The sonic signal is interpreted as the sonic shock wave that is generated when the speed of the fireball exceeds the speed of sound. The first observation was made on 17 January 2009 when a meteoroid entered the atmosphere from space above the Baltic Sea and landed

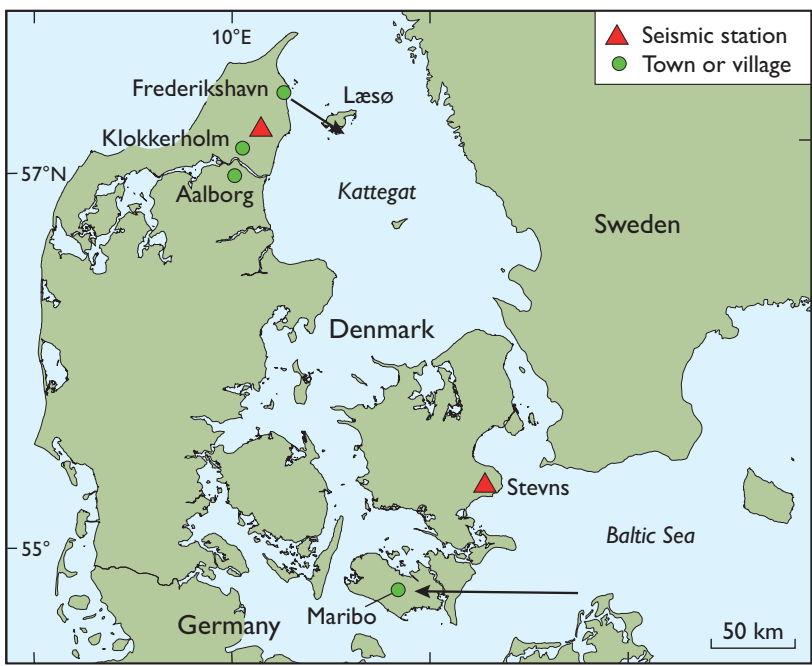

Fig. 1. Map of Denmark showing the location of seismic stations and towns mentioned in the text. The arrows show the paths of fireballs.
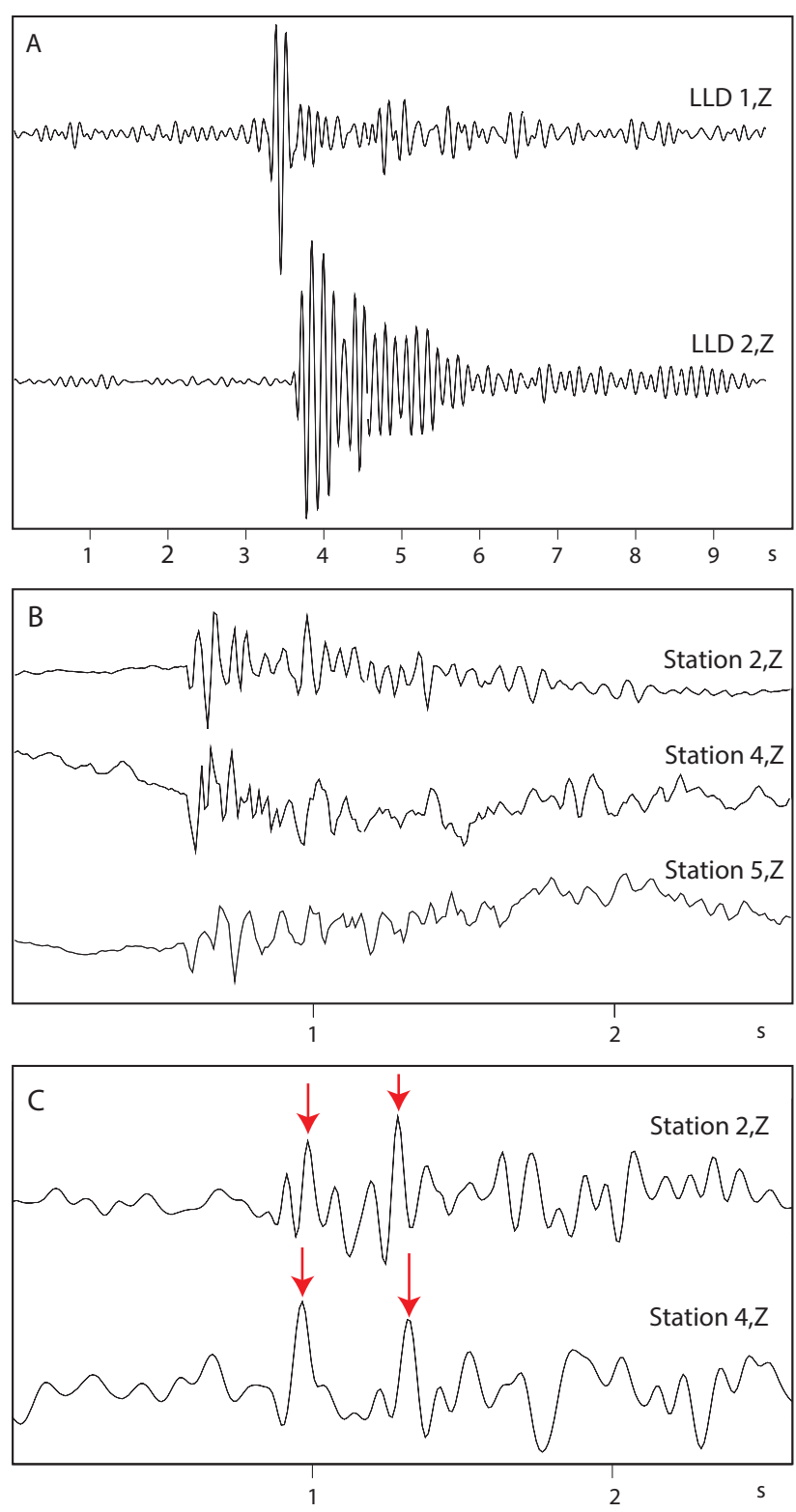

Fig. 2. A: Seismograms from the two seismic sensors that recorded the passing shock wave of the 2009 fireball. Data have been band-pass filtered from 5 to $10 \mathrm{~Hz}$. B: Seismograms from three seismic sensors that recorded the shock wave of the 2014 fireball showing the first motion downward on three stations. Data have not been filtered. C: The arrows mark the pulses of the $N$-wave of the 2014 fireball. Data were band-pass filtered from 1 to $10 \mathrm{~Hz}$. 




Fig. 3. Seismic recordings from six seismic stations of the shock wave caused by the fireball on 16 June 2014. Data are the up/down $\mathrm{Z}$ component of the data. Amplitudes are normalised and the data were band-pass filtered from 5 to $10 \mathrm{~Hz}$. The time is UTC.

near the town of Maribo, Lolland (Fig. 1), where a meteorite with a weight of $25.8 \mathrm{~g}$ was found (Haack 2012; Haack et al. 2012). The second meteoroid was recorded on 16 June 2014 on a small network of six seismic stations north of Aalborg, Jylland. This meteoroid entered the atmosphere south of Frederikshavn and possibly ended in the Kattegat south of the island of Læsø (Fig. 1). No meteorite was found.
The seismograms of the shock waves from the 2009 fireball are seen in Fig. 2A. They were recorded on the GEUS seismic station located on Stevns. The station is equipped with two vertical sensors installed 208 metres apart, with sensor LLD2 located $150^{\circ}$ south-east by south of sensor LLD1. The acoustic signal arrived $0.33 \mathrm{~s}$ later at LLD2 than at LLD1 which suggests that the source of the signal was located to the south-east of the stations. The duration of the signals differs by a factor of four, which might be an effect of the different conditions at the sites where the sensors are installed. The LLD1 signal is from the original sensor, located in a small vault dug into the field. The LLD2 signal is from an experimental installation of a similar sensor next to the wall of a large barn. The longer duration of this signal was probably caused by the resonance of the shock wave by the barn.

When seismic data from the 2014 fireball were first analysed, the lack of $S$-wave energy suggested that the source of the signals was a mine explosion in Kattegat. But closer inspection of the signals showed that the first motion of the detected $P$-wave was downward, consistent with dilatation at the source (Fig 2B). The expected first motion of the $P$-wave from an explosion is upward in response to the compression exerted by the source on the surroundings. An analysis of the signals recorded on the six stations, seen in Fig. 3, shows that the shock wave arrived at the stations from an almost easterly direction of approximately $96^{\circ}$, with an apparent surface velocity of $1255.8 \mathrm{~m} / \mathrm{s}$. Assuming a sound speed of $342.2 \mathrm{~m} / \mathrm{s}$ the incidence angle to the seismic stations is $15.9^{\circ}$ from vertical. These results fit well with the fireball observations published at http://stjerneskud.info. The observed fireball trajectory derived by Sørensen (2014) based on pho-

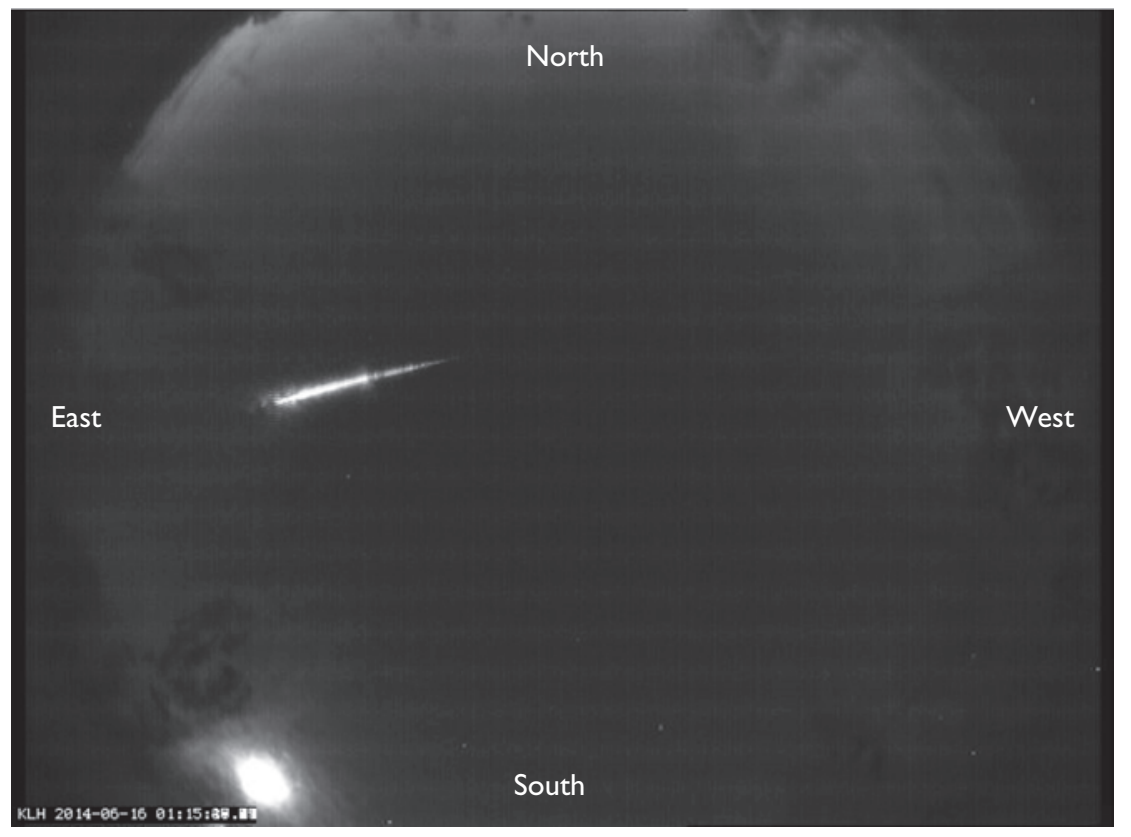

Fig. 4. Photograph showing the meteoroid trajectory. The photograph was taken with a specially designed fireball camera on 16 June 2014 at 1:15 p.m. local time, in Klokkerholm, Jylland. The camera was turned upward and equipped with a fisheye objective. The meteor was visible for 3.9 s. The image was created by stacking all video frames showing the fireball. Courtesy of Kim Lang, Klokkerholm and Anton Sørensen, http:// stjerneskud.info. 


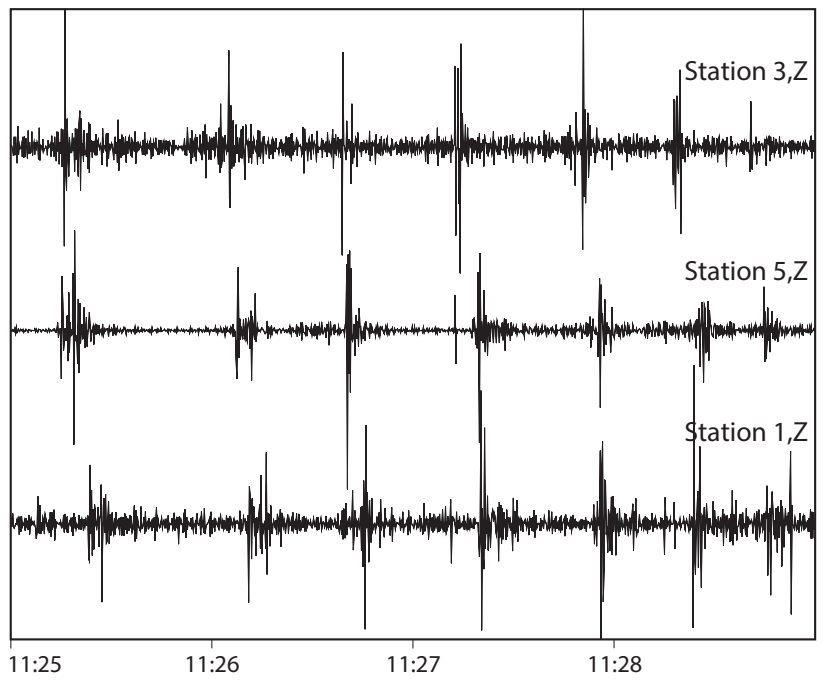

Fig. 5. Seismograms showing 4 minutes of data from the up/down sensor recorded at three stations as a thunderstorm passed by on 1 July, 2014. At least seven signals caused by thunder are seen. Time is UTC, data were band-pass filtered from 10 to $30 \mathrm{~Hz}$.

tographs taken at two locations in northern Jylland (Fig. 4) corresponds well with our calculation of the azimuth angle. The crossing of the azimuth and the trajectory suggest that the source of the shock wave came from an altitude of $46 \mathrm{~km}$ in the upper part of the stratosphere over the island of Læsø. But since sound in the atmosphere often follows nonlinear ray paths as seen by the low incidence angle, the derived altitude is very uncertain.

The changes in air pressure in the shock wave generate a seismic $P$-wave in the upper part of the Earth. Since the seismic $P$-wave travels faster than the shock wave, it can sometimes be detected just before the arrival of the shock wave as shown by, e.g. Kanamori et al. (1991). But in the data from the two fireballs that we have observed, we see no indication of $P$-wave signals arriving before the shock wave. As the sonic boom travels through the atmosphere, the change in pressure has an $N$-shaped pulse. At the conversion to seismic energy, the $N$-wave shows as two pulses on the seismogram (Kanamori et al. 1991; Cates \& Sturtevant 2002). Three examples of $N$-waves recorded after the 2014 fireball are shown in Fig. $2 \mathrm{C}$. These should not be confused with $P$-waves, which arrive through the ground.

\section{Thunder}

The six seismic stations north of Aalborg, installed in a network with a radius of $5 \mathrm{~km}$, have made it possible to detect signals that are normally regarded as noise, for instance thunder. Thunder couples to the ground like the sonic booms from, e.g. meteoroids, but since lightning often covers very large areas and occurs in sequences, the seismic signal consists of many peaks and is less impulsive (e.g. Kappus \& Vernon 1991). An example of at least seven thunder signals within a short time window is seen in Fig. 5. The distance to a thunderstorm that will generate an observable signal depends on the power of the acoustic signal released by the thunder and the composition of the atmosphere at the time of the thunder, since changes in the atmosphere can dampen or amplify acoustic signals in different directions. Most of the thunder we have observed occurred close to our seismic stations, but we have also observed thunder up to $30 \mathrm{~km}$ from a seismic station. The thunder signals differ from earthquake signals and explosions by the absence of body waves and are characterised by an apparent surface velocity around the speed of sound. It is the apparent surface velocity of the thunder signals that discriminates the seismic signals from other noise signals, such as traffic. Since the distance between seismic stations is usually long $(50 \mathrm{~km})$, thunder will most often only be recorded by a single seismic station, whereas a minimum of three stations is needed to estimate the apparent surface velocity. It is therefore normally not possible to positively identify sonic waves.

In order to identify thunder signals we verify the observations with the lightning measurements performed by the Danish Meteorological Institute. Maps of observed lightning in Denmark are presented on the institute's webpage (http://www.dmi.dk/vejr/maalinger/lyn/).

\section{Discussion}

The signals caused by sonic booms only constitute a small fraction of the observed seismic events in the GEUS earthquake database. But when they occur they must be identified so that they do not contaminate the seismic data.

The sonic boom from the fireball on 16 June 2014 was not reported by any persons. The seismic recordings only contain signals up to $50 \mathrm{~Hz}$ which is close to the lower limit of the human hearing range (on average $31 \mathrm{~Hz}$ ). The frequency spectra in Fig. 6 show that the recorded seismic signal of the meteoroid shock wave on average contained less energy above $31 \mathrm{~Hz}$ than for instance a thunder signal recorded on 1 November 2014 . At around $15 \mathrm{~Hz}$ the two signals have similar amplitudes, but again at lower frequencies the thunder signal is on average higher.

With an energy content lower than a thunder signal, the sonic boom was probably not audible to humans. Figure 6 also shows the spectra of the $P$-wave of a local magnitude 1.2 earthquake recorded on 4 August 2014, approximately 39 $\mathrm{km}$ from the seismic station. The spectra of the $P$-wave are 


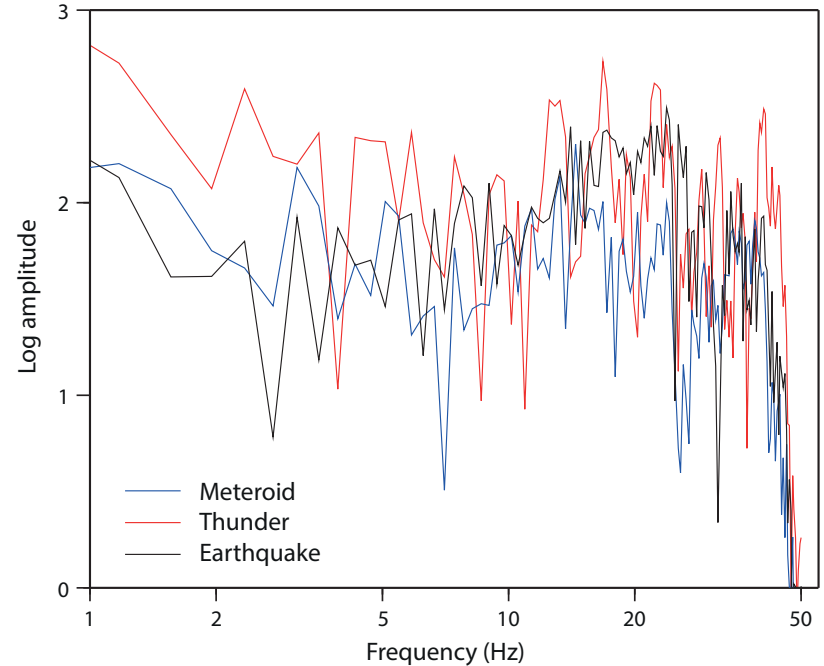

Fig. 6. Frequency spectra of meteoroid, thunder and earthquake waves. A time window of $2 \mathrm{~s}$ around the signal on the up/down $\mathrm{Z}$-sensor from Station 1 was used. The amplitude is uncorrected. The Nyquist frequency is $50 \mathrm{~Hz}$.

comparable to the thunder signal, at frequencies lower than $40 \mathrm{~Hz}$. Hearing such a signal would require a coupling of the energy from the ground to the air, which would introduce an energy loss. When people send GEUS reports on earthquakes sounds, they are often related to movements in buildings. GEUS did not receive any reports from this earthquake being felt or heard.

It is often the ground impact of meteors that is associated with danger, but the meteor that hit Chelyabinsk, Russia, on 15 February 2013 was a clear reminder that the shock wave may pose a significant risk. More than 1600 people were hurt from falling debris and over 7300 buildings were damaged. Seismic waves were observed at distances of more than 4000 $\mathrm{km}$. This corresponds to an earthquake magnitude of 3.6 (Heimann et al. 2013).

The challenge of marking seismic events of non-tectonic nature in the earthquake database remains and we are still not able to identify and mark them all. Although we have recorded explosions, glacial earthquakes, thunder and fireballs we still have not detected any footquakes in Denmark. Footquakes are seismic signals from sport events like football, an example comes from the 2006 African Cup. When Cameroon scored goals during the games, people in Cameroon who watched the games on TV jumped a lot and generated simultaneous signals on 20 seismic stations across the country (Euler 2007).

\section{References}

Cates, J.E. \& Sturtevant, B. 2002: Seismic detection of sonic booms. Journal of the Acoustical Society of America 111, 614-628.

Euler, G.G., Wiens, D.A. \& Lofton, K.M. 2007: Footquakes. IRIS Newsletter 1, p. 13.

Haack, H. 2012: Meteoritter - tidskapsler fra solsystemets oprindelse, 189 pp. Copenhagen: Gyldendal.

Haack, H. et al. 2012: Maribo - a new CM fall from Denmark. Meteoritics and Planetary Science 47, 30-50.

Heimann, S., González, Á., Wang, R., Cesca, S. \& Dahm, T. 2013: Seismic characterization of the Chelyabinsk meteor's terminal explosion. Seismological Research Letters 84, 1021-1025.

Kanamori, H., Mori, J., Anderson, D.L. \& Heaton, T.H. 1991: Seismic excitation by the space shuttle Columbia. Nature 349, 781-782.

Kappus, M.E. \& Vernon, F.L. 1991: Acoustic signature of thunder from seismic records. Journal of Geophysical Research-Atmospheres 96, 10989-11006.

Sørensen, A.N. 2014: http://www.stjerneskud.info/fireball/ event2014-06-16-01-15/

Authors' address

Geological Survey of Denmark and Greenland, Øster Voldgade 10, DK-1350 Copenhagen K, Denmark. E-mail:pv@geus.dk 